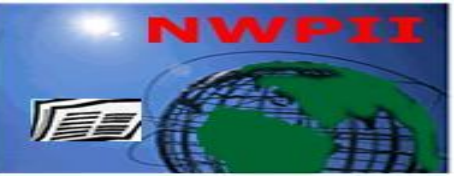

American Journal of Biomedical Sciences

ISSN: 1937-9080

nwpii.com/ajbms

\title{
Effect of Transdermally Delivered Aspirin on Blood Coagulation Parameters
}

\author{
Areeg A. Shamsher*, Naseem A. Charoo, Kanchan Kohli, Krishna Pillai, Ziyaur Rahman
}

Faculty of Pharmacy, Jamia Hamdard University, New Delhi-110062, India

*Corresponding author

(Author is presently affiliated to following University)

Department of Pharmacology,

Khartoum College of Medical Sciences,

Aljerief West, Ist Block Number 398

P.O. Box 10995

Khartoum, Sudan

E-mail: areeg102@yahoo.co.in

Received: 2 July 2009; | Revised: 16 August 2009; | Accepted: 15 December 2009

\begin{abstract}
The efficacy of oral aspirin treatment in the secondary prevention of cardio and cerebro vascular disease is well known. However oral administration is often associated with abdominal discomfort. The feasibility of delivering aspirin transdermally from eudragit and polyvinyl acetate (PVA) matrix-type patches to enhance its antithrombotic efficiency of aspirin was investigated. Transdermal films containing mixture of eudragit RL: eudragit RS and polyvinyl acetate were fabricated. Eudragit RL: eudragit RS (5:1) films containing 30 $\mathrm{mg} /$ transdermal patch aspirin showed maximum release $\left(11.89 \pm 1.1 \mu \mathrm{g} / \mathrm{cm}^{2}\right)$ after $24 \mathrm{hrs}$ as compared to PVA films. With regards to appearance eudragit films were also wrinkle free, uniform, flexible and transparent with good adhesion property to skin. The effect of turpentine oil and lemon oil at different concentrations on the in vitro percutaneous absorption of aspirin from eudragit copolymer patches through rat skin was investigated. Two formulation containing $50 \mathrm{mg} /$ transdermal patch ASA with $0.042 \mathrm{ml}$ turpentine oil and $0.042 \mathrm{ml}$ lemon oil showed a significantly higher flux of ASA $4.22 \mu \mathrm{g} / \mathrm{cm}^{2} / \mathrm{hr}$ and $38.52 \mu \mathrm{g} / \mathrm{cm}^{2} / \mathrm{hr}$ respectively. The optimized formulations influenced the blood coagulation parameters (bleeding time, prothrombin time, Activated partial prothrombin time) significantly by means of affecting both the extrinsic coagulation system and the intrinsic coagulation system as compared to orally administered and control gel formulations.
\end{abstract}

Keywords: Transdermal; Aspirin; Penetration enhancers; Antiplatelet. 


\section{Introduction} manifest as coronary heart disease (e.g. angina pectoris, myocardial infarction, sudden death), cerebro-vascular disease (e.g. stroke and transient ischaemic attack) or peripheral vascular disease (e.g. claudication and critical limb ischaemia). Atherosclerosis is a progressive inflammatory disorder of the arterial wall that is characterized by focal lipid-rich deposits of atheroma that remain clinically silent until they become large enough to impair arterial perfusion or until ulceration or disruption of the lesion results in thrombotic occlusion or embolisation of the affected vessel.

The possibility that anti-inflammatory compounds might be effective in the prevention of cardiovascular disorders, including myocardial infarction, stroke and thrombosis was anticipated when aspirin was found to reduce platelet aggregation induced by several physiological stimuli [1]. The efficacy of oral aspirin treatment in the secondary prevention of cardio and cerebro vascular disease has been established [2, 3].

The blood-thinning properties of aspirin are based on its inhibition of prostaglandin synthesis in the blood platelets. Platelet aggregation plays a crucial role in thrombosis, hence usefulness of aspirin as anti-aggregating agent [4].

The most frequently reported side effects of aspirin, when administered orally, are abdominal discomfort along with other gastrointestinal effects. This has limited its widespread clinical use for the prevention of cardiovascular events [5]. Thus, the use of low dose aspirin daily, which is virtually devoid of a measurable antiinflammatory effect, has been investigated [6].

Transdermal delivery offers an alternative route for the administration of low-dose aspirin for the treatment of atherosclerotic vascular disease. It will retain the inhibitory effect of aspirin on platelet COX-2 and minimize that on vascular COX-1, thus continuous low-dose aspirin therapy can be used without the reported risks on GI tract $[7,8]$.

Aspirin is polar at physiological $\mathrm{pH}$ and it is rapidly hydrolyzed to salicylic acid in the skin, which is rich in enzymes, like esterases. Hence it is not a good candidate for this form of delivery.
Atherosclerotic vascular disease may

However, little aspirin is required per day to suppress platelet COX, particularly when it is delivered continuously. In vitro studies showed that the skin acts as a reservoir for aspirin, with as much as $10 \%$ to $15 \%$ absorbed over 24 to 48 hours after a single application [9]. A 1993 study showed that aspirin in monohydroxy alcohols applied directly to the skin surface, selectively inhibited the activity of cyclooxygenase in platelets [10]. However, a large dose (750mg) of aspirin was required, which necessitated a large volume applied over a wide area.

Aspirin in a transdermal patch (surface area of $50 \mathrm{~cm}^{2}$ ) at a lower dose ( $84 \mathrm{mg}$ and $120 \mathrm{mg}$ ) without and with $12 \%$ limonene as penetration enhancer respectively, was also found to induce marked suppression of platelet cyclo-oxygenase [11], though the bioavailability of aspirin applied to the skin was only $20 \%$.

Studies have focused on the synthesis of stable aspirin analogues and derivatives (esters and anhydrides) the idea being that these molecules; would transverse the skin efficiently, yielding ASA subcutaneously [12]. These compounds were predicted to release the more polar ASA by their hydrolysis within the skin. Aspirin anhydride was found to release significant amount of ASA and less salicylic acid over the six hours time frame.

The inherent barrier properties of the skin, the gastric irritation and ulceration and the fact that aspirin is rapidly hydrolyzed to salicylic acid (SA) during transport [13], has inspired us to design the present study. To accomplish these objectives, transdermal therapeutic systems of aspirin were prepared. The influence of formulation parameters on the release characteristics of aspirin was examined.

\section{Materials and methods}

\subsection{Materials}

Aspirin was kindly gifted by Wings Pharmaceuticals, New Delhi. Turpentine and lemon oil was purchased from Nice Chemicals New Delhi. Different grades of Eudragits and PVA were purchased from Aldrich (St. Louis, MO). All other chemical were of analytical or higher grade.

(C) 2010 by NWPII. All rights reserved 


\subsection{Formulation and evaluation of placebo films}

To determine the optimum combination of polymers, plasticizer and solvents, placebo films were formulated. Films of PVA and eudragit RL 100/RS 100 were casted on teflon surface. The polymer and plasticizers were accurately weighed in different proportions and dissolved in appropriate solvent. The required solution for one patch was poured into the glass ring (internal diameter $1.33 \mathrm{~cm}$ ) kept on the teflon block and dried at $15^{\circ} \mathrm{C} \pm 2^{\circ} \mathrm{C}$ and $\mathrm{RH} 30 \%$ in temperature controlled humidity chamber. An inverted funnel plugged with the cotton was placed over the petridish to prevent rapid evaporation of solvent. This minimized the chances of cracking or wrinkling of the films and allowed uniform evaporation of the solvents. The formulas of various placebo films are given in table 1 .

The films were evaluated for thickness, folding endurance, tensile strength and visual examination.

Table 1: Formulae of the placebo films of eudragits

\begin{tabular}{|c|c|c|c|c|c|c|c|c|c|c|c|}
\hline S. & Ingredients & Weig & $t$ in $g$ & er patc & & & & & & & \\
\hline No & & A & B & $\mathrm{C}$ & D & $\mathbf{E}$ & $\mathbf{F}$ & G & $\mathbf{H}$ & I & $\mathbf{J}$ \\
\hline 1. & Eudragit RL 100 & 0.0105 & 0.0105 & 0.0168 & 0.0168 & 0.0210 & - & - & - & - & - \\
\hline 2. & Eudragit RS 100 & - & - & 0.0042 & 0.0042 & 0.0042 & - & - & - & - & - \\
\hline 3. & $\begin{array}{l}\text { Polyvinylacetate } \\
\text { (M. wt. } 4500 \text { ) }\end{array}$ & - &.- & - & - & - & 0.0105 & 0.0105 & 0.0168 & 0.0168 & 0.0168 \\
\hline 4. & Diethylphthalate* & 0.0011 & 0.0018 & 0.0011 & 0.0017 & 0.0030 & 0.0011 & 0.0003 & 0.0004 & - & 0.0004 \\
\hline 5. & Ethanol $(\mathrm{ml})$ & 0.126 & 0.126 & 0.168 & 0.168 & 0.126 & - & - & - & - & $\cdot$ \\
\hline 6. & Acetone $(\mathrm{ml})$ & 0.084 & 0.084 & 0.042 & 0.042 & 0.084 & - & - & - & - & - \\
\hline 7. & Chloroform (ml) & - & - & - & - & - & 0.21 & 0.21 & 0.21 & 0.21 & 0.21 \\
\hline
\end{tabular}

Drying temperature $=15 \pm 2^{0} \mathrm{C}$

Relative humidity $=30 \% \mathrm{RH}$

Drying time $=24$ hours approximately

*Calculated on the basis of $\%$ polymer i.e. $(10 \%, 17 \%, 5 \%, 8 \%, 12 \%, 10 \%, 3 \%, 2.5 \% \& 2.5 \%$ for formulae No. A, B, C, D, E, F, G, H \& J respectively).

On the basis of preliminary studies the optimized plasticizer (diethyl phthalate), polymer (eudragit RL100 and RS100), penetration enhancers, and drug were dissolved in ethanol \& acetone $(3: 2)$ and films were casted on Cotron $\left(3 \mathrm{M}^{\mathrm{TM}}\right.$, USA), a drug impermeable backing membrane placed on teflon surface. The films were dried at $15 \pm 2^{\circ} \mathrm{C} \& 30 \% \mathrm{RH}$ in temperature controlled humidity chamber.

After $24 \mathrm{hrs}$, the films were cut to appropriate size with the help of the die. The exposed side of the patch was covered by fluoropolymer coated polyester release liner $\left(3 \mathrm{M}^{\mathrm{TM}}\right.$, USA). The transdermal patch was placed in laminated aluminum foil. The formula of transdermal patches is given in table 2 .

\subsection{In vitro permeation studies of formulated ASA patches}

In vitro drug skin permeation studies were carried out in modified Keshary- Chien cell. Abdominal rat skin was used for the studies. Rats were sacrificed by placing them in an ethersaturated chamber. The abdominal hair was removed with an electrical hair clipper, and the full-thickness skin was separated surgically. The separated skin was cleaned from subcutaneous fat, muscle and vasculature, and were carefully wrapped in aluminum foil and kept frozen at $20^{\circ} \mathrm{C}$ until use. Skin samples were defrosted, and sandwiched between donor and receptor compartments of modified vertical Keshary Chien diffusion cells (effective surface area of $9.79 \mathrm{~cm}^{2}$ ), with the epidermis facing the donor compartment.

Receiver compartment consisted of $30 \mathrm{ml}$ of isotonic phosphate buffer of $\mathrm{pH}$ 7.4: ethyl alcohol $(90: 10 \% \mathrm{v} / \mathrm{v})$ maintained at $37 \pm 0.5^{\circ} \mathrm{C}$ and was magnetically stirred at $500 \mathrm{rpm}$. Aliquots $(1 \mathrm{ml})$

(C) 2010 by NWPII. All rights reserved. 
were withdrawn, and replaced with the same volume of fresh receptor medium. The samples were immediately analyzed for ASA content by HPLC [14].

Table 2: Formulae of ASA transdermal patches

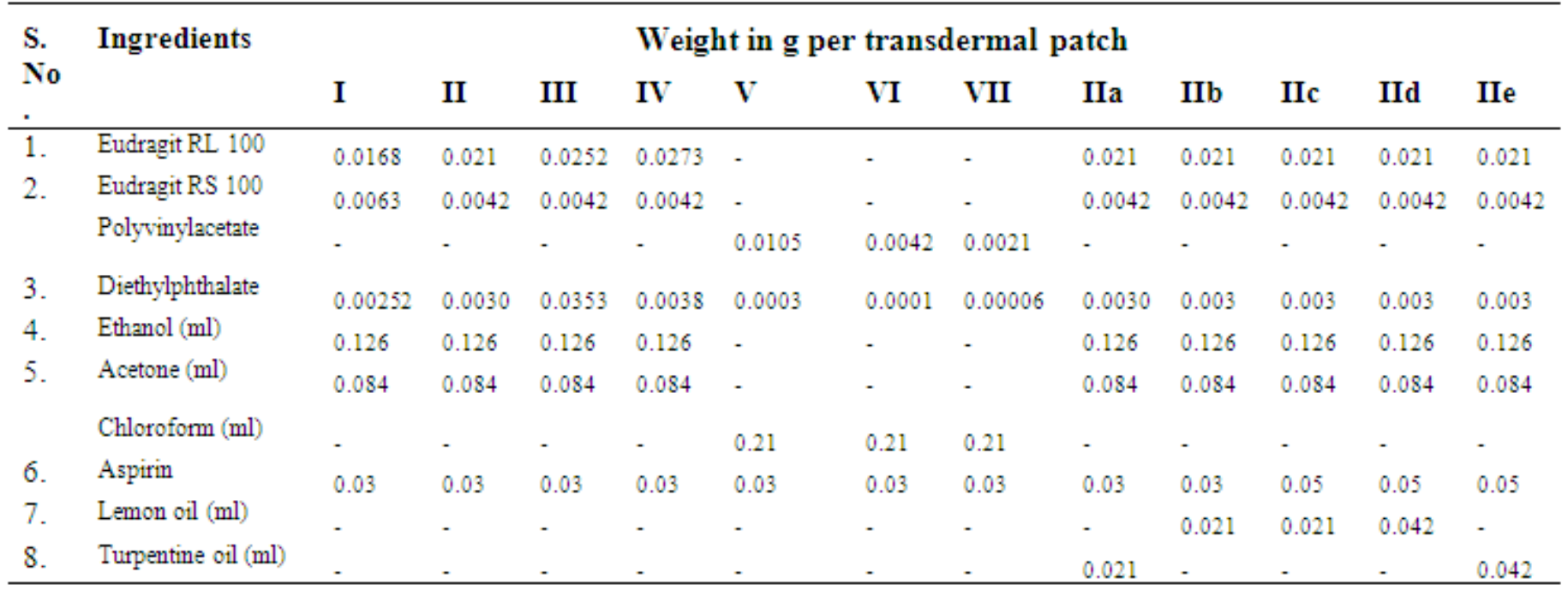

Drying temperature $=15 \pm 2{ }^{\circ} \mathrm{C}$

Relative humidity $=30 \% \mathrm{RH}$

Drying time $=24$ hours approximately

The skin samples were equilibrated with the receptor medium for 6 hours. A blank receptor sample of $1 \mathrm{ml}$ was withdrawn and analyzed to ensure the absence of any residual absorbance. The receptor phase was replaced every 30 minutes. After 6 hours, no absorbance was shown, indicating the complete stabilization of the skin.

Transdermal patches measuring $1.39 \mathrm{~cm}^{2}$ surface area were applied on the skin mounted on Keshary Chien diffusion cell.

\subsection{Pharmacodynamic studies}

\subsubsection{Mice tail bleeding time (BT)}

Bleeding time is an in vivo measurement of interaction between the platelets and vessel wall [15]. This experiment was performed at room temperature. Animals were divided into 5 groups each containing 8 mice. Group 1 served as control and $10 \mathrm{mg}$ ASA in $1 \% \mathrm{w} / \mathrm{v}$ CMC suspension in water was administered orally to group 2 animals. To group 3, 4 and 5, transdermal patches II, IIe and IId were applied respectively.

Mice were slightly ether anesthetized, and abdominal hair was carefully removed with electric clipper, they were fasted overnight. On the next day, the transdermal patch formulations containing $10 \mathrm{mg}$ of ASA in eudragit copolymers were applied on the abdominal area of $9 \mathrm{~cm}^{2}$ gently. ASA in carboxymethyl cellulose (CMC) suspension was also administered orally.

Bleeding was induced by transecting exactly $0.5 \mathrm{~cm}$ of the distal tip of the tail of an adult mouse at $0 \mathrm{hr}, 4 \mathrm{hrs}$ and $24 \mathrm{hrs}$ from the administration of the drug at different places across the tip of the tail. The tails were then gently blotted with filter paper at the interval of 30 seconds and the time in seconds to cessation of bleeding was noted. The sampling points reflect the constraints for number of incision that can be made to the mice tail.

\subsubsection{Rat prothrombin time (PT)}

Rats were slightly ether anesthetized, and abdominal hair was carefully removed with electric clipper, they were fasted overnight. On the next day, the transdermal patch formulations containing $8 \mathrm{mg}$ of ASA in eudragit copolymers were applied on the abdominal area of $9 \mathrm{~cm}^{2}$ gently. ASA in CMC suspension was also administered orally. 
The blood was then collected by venipuncture of ketamine anesthetized rats at $0 \mathrm{hr}$ and $24 \mathrm{hrs}$ into centrifuge tube containing $0.5 \mathrm{ml}$ of $3.8 \%$ sodium citrate to make a ratio of 1:9 (sodium citrate: blood), mixed evenly and centrifuged immediately at $3000 \mathrm{rpm}$ for 10 minutes at room temperature. Plasma was obtained and frozen (if not assayed immediately) in $50 \mu \mathrm{l}$ aliquots at $70^{\circ} \mathrm{C}$ until assayed.

All samples of rat plasma were thawed at the time of testing. $50 \mu \mathrm{l}$ of plasma was incubated at $37^{\circ} \mathrm{C}$ for 5 minutes in Coag Uno coagulation analyzer, (Erba Transasia, India) containing 100 $\mu 1$ of Thromborel ${ }^{\circledR} S$ reagent (Dade Behring Inc., USA) containing mixture of thromboplastin and $30 \mathrm{mmol} / \mathrm{L} \mathrm{CaCl}_{2}$. The time in seconds to formation of a fibrin clot was then noted down directly from the coagulation analyzer.

\subsubsection{Activated partial thromboplastin time (APTT)}

Rats were slightly ether anesthetized, and abdominal hair was carefully removed with electric clipper, they were fasted overnight. On the next day, the transdermal patch formulations containing $8 \mathrm{mg}$ of ASA in eudragit copolymers were applied on the abdominal area of $9 \mathrm{~cm}^{2}$ gently. ASA in CMC suspension was also administered orally. The blood was then collected and processed as previously explained to obtain the plasma.

$50 \mu \mathrm{l}$ of plasma was incubated at $37^{\circ} \mathrm{C}$ for 5 minutes in Coag Uno coagulation analyzer (Erba Transasia, India), with $50 \mu 1$ of Pathromtin ${ }^{\circledR}$ SL reagent (containing vegetable phospholipids plus other ingredients). The tube was then incubated at $37^{\circ} \mathrm{C}$ for 5 minutes. On addition of $50 \mu \mathrm{l}$ of 30 $\mathrm{mmol} / \mathrm{L} \mathrm{CaCl} \mathrm{Cl}_{2}$ recalcification occurs. The time in seconds from the addition of $\mathrm{CaCl}_{2}$ solution was then noted directly from the coagulation analyzer.

\subsection{Data analysis}

\subsubsection{Determination of permeation parameters for in vitro release studies}

The steady state flux was determined from the slope of the linear portion of a cumulative amount permeated versus time plot. The lag time $\left(\mathrm{T}_{\mathrm{lag}}\right)$ was determined by extrapolating the linear portion of the cumulative amount permeated versus time curve to the abscissa.

\subsubsection{Pharmacodynamic analysis}

Effect of ASA on blood coagulation data is presented as mean \pm SD. Statistical analysis was performed using Analysis of Variance (ANOVA) followed by Dunnett's test and students Newman Keuls multiple comparison test.

\section{Results}

Due to its GI toxicity, there has been a reluctance to recommend aspirin as a primary antithrombotic drug. Although the frequency is relatively small for low dose aspirin, GI bleeding occurs at doses as low as $30 \mathrm{mg}$ / day [16]. Orally administered aspirin requires high and frequent dosing because it undergoes extensive presystemic hydrolysis in the gut and the liver into salicylic acid, which is devoid of antiplatelet activity [17].

Transdermal application of aspirin permits slow absorption of aspirin and presystemic acetylation of platelet cyclooxygenase within the portal circulation, potentially avoiding deleterious effects on gastric and systemic prostaglandin synthesis [11].

Hence, to increase the antithrombotic efficiency of aspirin in a more convenient mode of application, we have investigated the feasibility of delivering aspirin transdermally by a matrix-type patch using turpentine oil and lemon oil as penetration enhancers.

\subsection{Selection of solvent systems and casting surface}

Prior to the formulation of the TDDS, various solvents were screened out for the drug, polymers and plasticizers.

Aspirin is freely soluble in ethanol (95\%), soluble in chloroform and slightly soluble in water. Acrylate polymers are soluble in alcohol, acetone and dichloromethane and insoluble in carbon tetrachloride, Petroleum ether and benzene. Polyvinylacetate (PVA) is soluble in alcohol, chloroform and carbon tetrachloride. Diethylphthalate suitably plasticized eudragits \& polyvinylacetate films and was found to be 
miscible in the mixture of alcohol and acetone, and chloroform.

During preliminary work, a number of substrates including mercury, teflon and glass were tried for the film formulation. The polymers and plasticizers were dissolved in solvent systems and poured on the teflon blocks, glass plates and glass rings placed on the surface of mercury in a petridish. Teflon blocks were found suitable for the casting of films as the films were found uniform, flexible and were easy to remove.

On the basis of above facts eudragit films were casted on teflon block using ethanol \& acetone (3:2) as the solvent and PVA films were casted using chloroform as the solvent. Diethylphthalate was used as the plasticizer in both the cases.

Different conditions were tried for solvent evaporation. It was found that at $15^{\circ} \mathrm{C}$ and $30 \%$ RH (in a humidity controlled chamber) the crystallization of aspirin was substantially minimized. Inverted funnels were placed over the films in order to control the evaporation of solvent. Evaporation rate was further controlled by placing loose cotton plugs on the neck of the funnels.

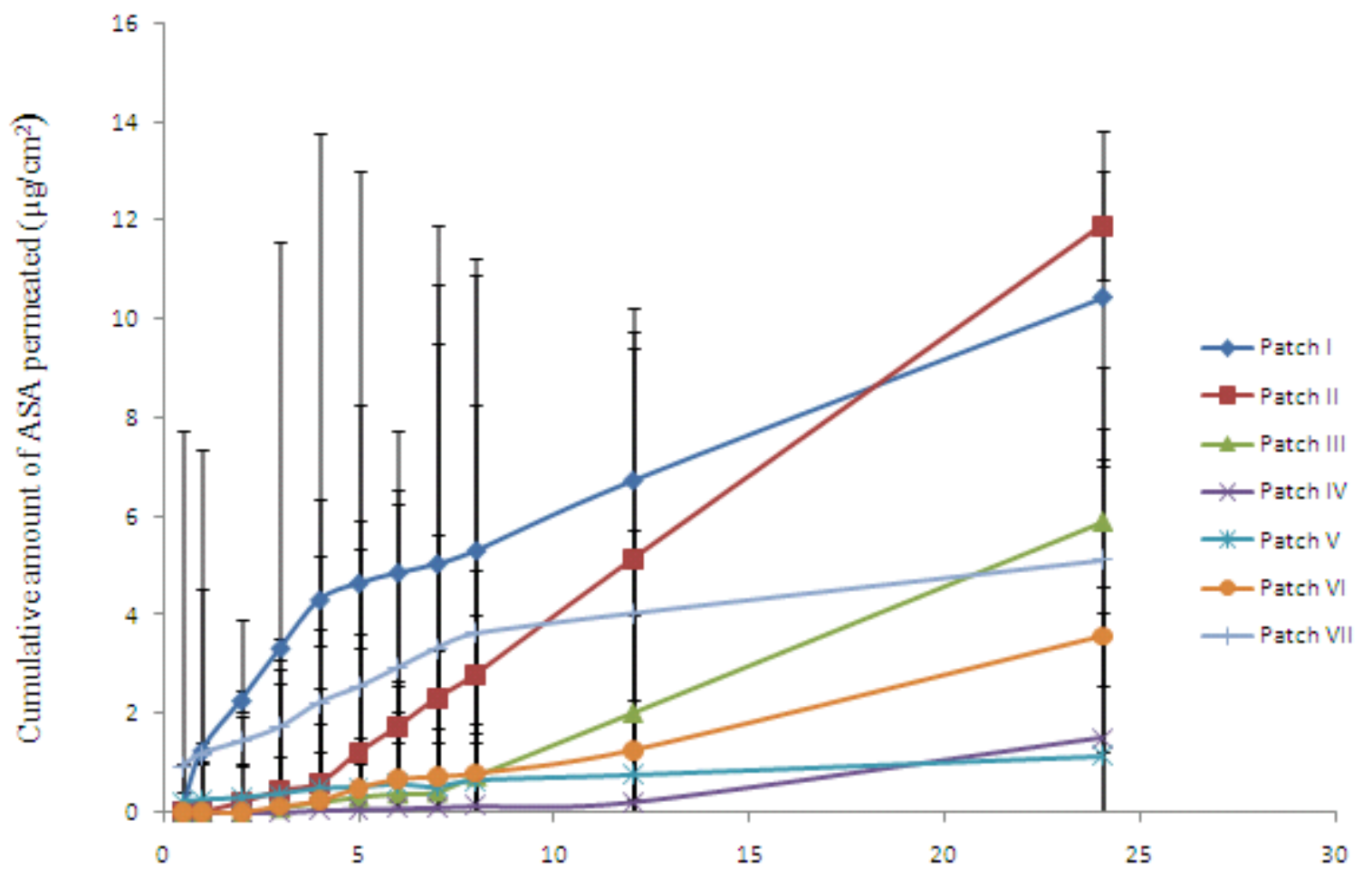

Time (h)

Fig. 1: In vitro permeation of ASA through rat skin from eudragit films.

\subsection{Fabrication of films}

Among the surfaces tried for film casting, teflon surface was found to be the most appropriate. Since the drug and polymer could be dissolved in common solvent, matrix type of transdermal therapeutic system was developed.

Placebo films of PVA and eudragit were prepared and evaluated for the physical characteristics viz. folding endurance, tensile strength, thickness and visual appearance.
Appropriate properties of the polymers, plasticizers and solvents were determined. Eudragit RL and RS polymers in film E and PVC film No. $G$ were found to result in wrinkle-free, flexible, uniform, transparent films with good adhesion to skin. Hence, films $\mathrm{E}$ and $\mathrm{G}$ were chosen for further optimization and release enhancement studies. Diethyl phthalate in proportion of $12 \% \mathrm{w} / \mathrm{w}$ and $3 \% \mathrm{w} / \mathrm{w}$ were found suitable for eudragit and PVA films respectively. 


\subsection{In vitro permeation of ASA from eudragit RL \& RS films}

These experiments were carried out to evaluate the effect of concentration variation of polymers and adjuvants on the transdermal release of ASA and to scrutinize the optimized formulation. Various transdermal films of ASA were prepared by using eudragit RL \& RS in organic solvent systems as mentioned previously.

Fig. 1 shows the cumulative permeated amount of ASA from different films across rat skin plotted against time. The resulting figure indicates much higher release from films containing eudragit RL \& RS co-polymers in different concentrations (films I, II and III) than films prepared with PVA (films V, VI, and VII).

With a concentration ratio of 5:1 (eudragit RL: eudragit RS), film II, containing $30 \mathrm{mg} /$ patch ASA showed maximum release $(11.89 \pm 1.1 \mu \mathrm{g} /$ $\mathrm{cm}^{2}$ ) after 24 hours. Further increase in the concentration of eudragit RL 100 to 0.0273 $\mathrm{gm} /$ patch keeping the concentration of eudragit RS 100 constant at $0.0042 \mathrm{gm} /$ patch (film IV) led to reduction in the release $\left(1.50 \pm 6.3 \mu \mathrm{g} / \mathrm{cm}^{2}\right)$ of ASA after 24 hours, this means that at higher concentration no further release will be facilitated. The mathematical interpretation of curves in terms of flux values, lag time and \% cumulative amount of ASA permeated are given in table 3 .

Table 3: In vitro permeation parameters of ASA transdermal patches

\begin{tabular}{lllll}
\hline $\begin{array}{l}\text { Formulation } \\
\text { Code }\end{array}$ & Flux $\left(\boldsymbol{\mu g} / \mathbf{c m}^{\mathbf{2}} \mathbf{h r}\right)$ & $\begin{array}{l}\text { Lag } \\
\text { (hours) }\end{array}$ & $\begin{array}{l}\text { time } \\
\text { Cumulative } \\
\text { amount of } \\
\text { permeated }\end{array}$ & $\begin{array}{r}\% \\
\text { ASA }\end{array}$ \\
\hline Patch I & $0.31 \pm 0.4$ & NA & 0.34 & \\
Patch II & $0.56 \pm 5.25$ & NA & 0.39 & \\
Patch III & $0.32 \pm 0.06$ & 6.1 & 0.19 & \\
Patch IV & $0.07 \pm 4.5$ & 11.0 & 0.05 & \\
Patch V & $0.03 \pm 0.02$ & NA & 0.04 & \\
Patch VI & $0.19 \pm 1.1$ & 5.9 & 0.12 & \\
Patch VII & $0.10 \pm 0.07$ & NA & 0.17 & \\
Patch IIa & $0.45 \pm 2.0$ & NA & 0.46 & \\
Patch IIb & $1.38 \pm 0.13$ & 3.6 & 0.97 & \\
Patch IIc & $16.82 \pm 1.45$ & 2.0 & 7.92 & \\
Patch IId & $38.52 \pm 0.98$ & 1.8 & 16.66 & \\
Patch IIe & $4.22 \pm 0.43$ & 3.8 & 1.62 & \\
\hline
\end{tabular}

The flux value for films VII $(0.10 \pm 0.07$ $\left.\mu \mathrm{g} / \mathrm{cm}^{2} / \mathrm{hr}\right)$ and VI $\left(0.19 \pm 1.1 \mu \mathrm{g} / \mathrm{cm}^{2} / \mathrm{hr}\right)$ containing 0.0021 and $0.0042 \mathrm{gm} /$ patch PVA respectively, was considerably low as compared to films formulated with eudragit co-polymers (I, II, III).

In film $\mathrm{V}$, the flux value $(0.03 \pm 0.02$ $\mu \mathrm{g} / \mathrm{cm}^{2} / \mathrm{hr}$ ) was further decreased on addition of higher concentration of PVA (0.0105 gm/patch).

Of various transdermal films tested, film II showed maximum transdermal flux value of 0.56 $\pm 5.25 \mu \mathrm{gg} / \mathrm{cm}^{2} / \mathrm{hr}$ with higher $\%$ cumulative permeated value of 0.39 .
3.4 In vitro permeation of ASA from the transdermal patches containing different penetration enhancers (turpentine oil and lemon oil)

The effect of turpentine oil and lemon oil at different concentrations on the in vitro percutaneous absorption of aspirin through rat skin is shown in table 3 and Fig.2.

Matrices of ASA (patch IIa and IIe) containing $0.021 \mathrm{ml} \& 0.042 \mathrm{ml}$ turpentine oil and $30 \mathrm{mg} /$ patch \& $50 \mathrm{mg} /$ patch ASA respectively were subjected to in vitro diffusion testing. The increase in cumulative permeated amount of ASA over 24 hours was observed from 11.89 \pm 1.1 
$\mu \mathrm{g} / \mathrm{cm}^{2}$ to $52.73 \pm 5.2 \mu \mathrm{g} / \mathrm{cm}^{2}$ over 24 hours (Patch IIe). Almost $1.62 \%$ of the drug was found to permeate across the rat skin over $24 \mathrm{hrs}$.
Table 3 also shows a significantly higher flux of ASA from patch IIe (4.22 \pm 0.43 $\mu \mathrm{g} / \mathrm{cm}^{2} / \mathrm{hr}$ ) than that of patch IIa and patch II (without enhancer).

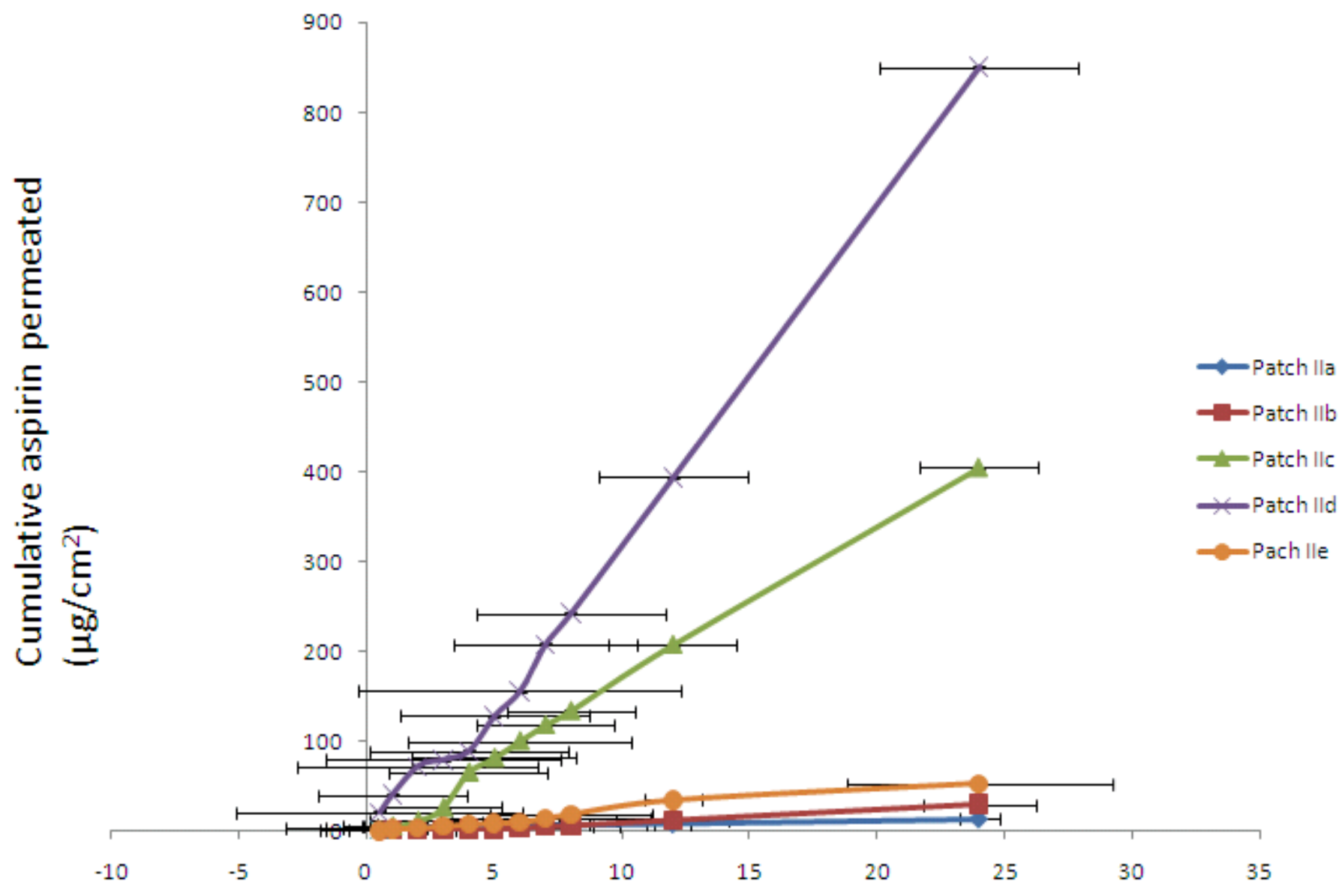

Fig 2: In vitro permeation of ASA through rat skin from different eudragit formulations containing penetration enhancers.

The cyclic monoterpene, d-limonene which is the main component of lemon oil and orange oil has been shown to increase the permeation of a number of nonsteroidal anti-inflammatory drugs including aspirin [11], diclofenac [18], ketoprofen [19] and ibuprofen [20]. D-limonene increases the permeation of drugs by disrupting the highly ordered structure of intercellular lipids and improving the partitioning of drugs in the stratum corneum [10].

As shown in fig. 2 effect of lemon oil on cumulative permeation of ASA was observed to be concentration dependent. Cumulative permeation of ASA over 24 hours was increased to $29.86 \pm 2.2 \mu \mathrm{g} / \mathrm{cm}^{2}$ (patch IIb) with $0.021 \mathrm{ml}$ lemon oil in the patch formulation containing 30 $\mathrm{mg} / \mathrm{patch}$ ASA.

In an ideal system, there is a linear relationship between the rate of diffusion and the concentration of diffusant. The maximum flux occurs when the concentration reaches the solubility limit [21]. The cumulative ASA permeated was further increased to $404.49 \pm 2.3$ $\mu \mathrm{g} / \mathrm{cm}^{2}$ (patch IIc) on increasing drug load to 50 $\mathrm{mg} / \mathrm{patch}$.

On increasing the lemon oil concentration to $0.042 \mathrm{ml} /$ patch the cumulative ASA permeated was almost doubled to $850.69 \pm 3.9 \mu \mathrm{g} / \mathrm{cm}^{2}$ (patch IId) and \% cumulative amount of aspirin permeated across rat skin from formulations IIc 
and IId containing $50 \mathrm{mg} / \mathrm{patch}$ ASA was increased significantly $(\mathrm{P}<0.001)$ to 7.92 and 16.66 respectively.

$0.042 \mathrm{ml}$ lemon oil showed a very strong enhancing effect when incorporated into patch IId formulation with maximum transdermal permeability flux of $38.52 \pm 0.98 \mu \mathrm{g} / \mathrm{cm}^{2} / \mathrm{hr}$ ) i.e. $0.92 \mathrm{mg} / \mathrm{cm}^{2}$ over 24 hours and a significantly low lag period of 1.8 hours.

\subsection{Influence of dermal ASA on bleeding time}

The initial bleeding time (BT) was $2.81 \pm$ 0.25 minutes. At 4 hours, of oral administration and transdermal application of ASA, oral aspirin at $10 \mathrm{mg} / \mathrm{kg}$, caused a significant increase in BT to $3.59 \pm 0.04$ minutes. $(\mathrm{P}<0.05$, Students Newman - Keuls multiple comparison test) as compared to the transdermal formulation of ASA, patch IId (3.27 \pm 0.05 minutes), patch IIe (3.25 \pm 0.11 minutes) and patch II ( $2.93 \pm 0.07$ minutes $)$ respectively (Fig 3).

At 24 hours of administrations, patch IId (BT: $4.02 \pm 0.26$ minutes) and patch IIe (BT: $3.8 \pm$ 0.13 minutes $)$, showed significantly $(\mathrm{p}<0.001$, Students - Newman- Keuls multiple comparison test) higher BT as compared to oral ASA (3.07 \pm 0.20 minutes) and patch II, containing no enhancer (3.05 \pm 0.08 minutes).

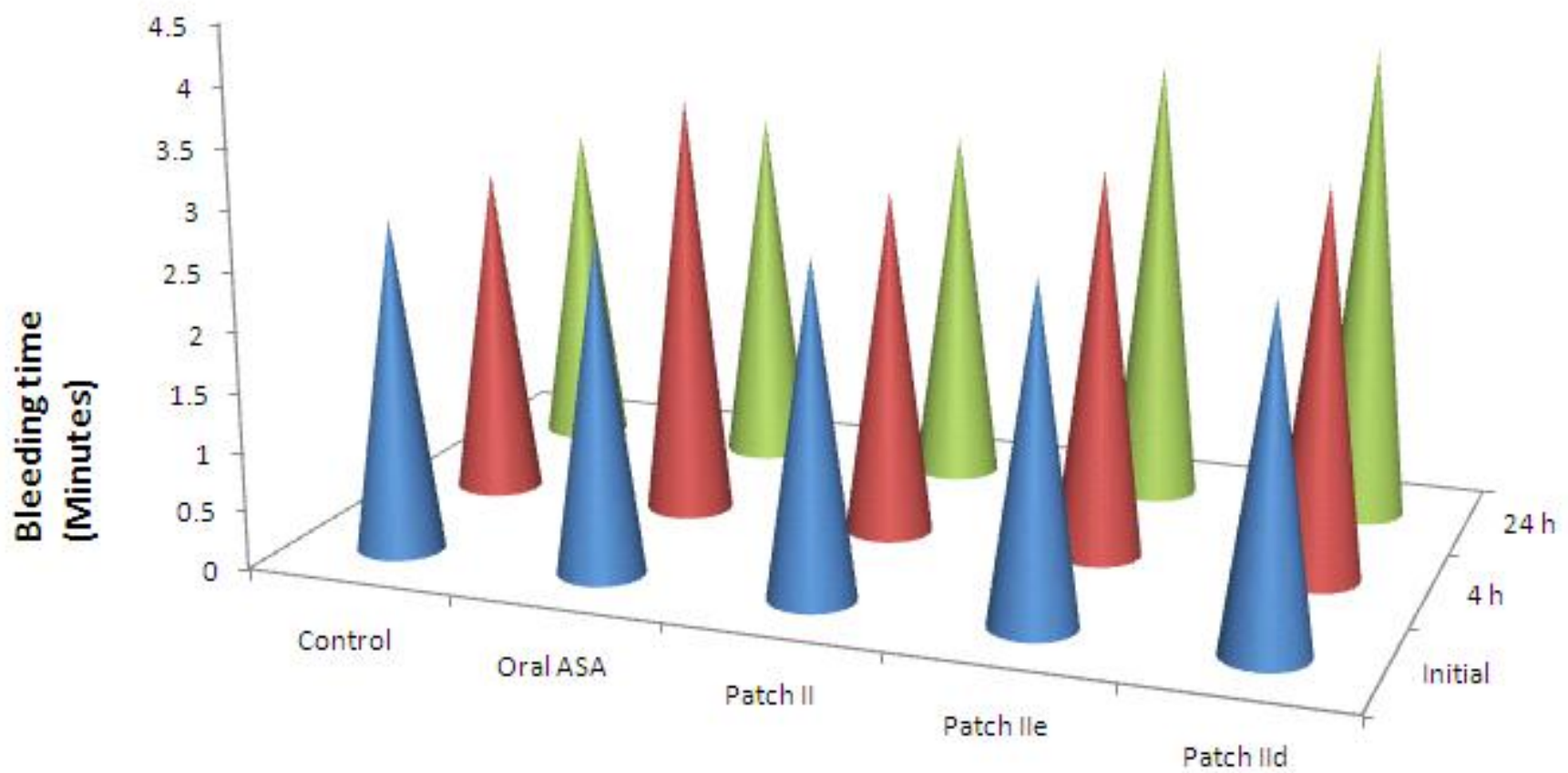

Fig 3: Influence of transdermal and oral ASA formulations on bleeding time as compared to control group

\subsection{Influence of dermal ASA on PT}

The test measures the clotting time of plasma in the presence of an optimal concentration of tissue extract (thromboplastin) and indicate the overall efficiency of the extrinsic clotting system (Factors II, V, VII and X). The test is also known to depend on reactions with factors V, VII and X, and on the fibrinogen concentration of the plasma [22]. The coagulation process is triggered by incubation of plasma with the optimal amount of thromboplastin and calcium. The time to formation of a fibrin clot is then measured.
It can be seen from table 4 that the transdermal application patch IId containing lemon oil resulted in a significant prolongation of prothrombin time $(10.2 \pm 0.10$ seconds, $\mathrm{P}<0.001)$ as compared to orally ingested ASA $(8.9 \pm 0.1$ seconds), control group ( $9.3 \pm 0.1$ secs.), patch II (9.47 \pm 0.06 secs), and patch IIe containing turpentine oil $(9.47 \pm 0.32 \mathrm{secs})$.

\subsection{Influence of dermal ASA on APTT}

The test measures the clotting time of plasma after the activation of contact factors but without added tissue thromboplastin, and so indicates the 
overall efficiency of the intrinsic pathway (Factors VIII and IX as well as the contact factors) [23].

Incubation of plasma with the optimal quantity of phospholipids and a surface activator leads to activation of factors of the intrinsic coagulation system. The addition of calcium ions trigger the coagulation process, the time to formation of a fibrin clot is measured.

APTT was also prolonged to $30.6 \pm 0.89$ and $32.78 \pm 3.25$ seconds after the transdermal application of patch IIe and IId respectively as compared to the control group $(28.3 \pm 1.9$ secs $)$ and patch II ( $27.0 \pm 4.11$ secs $)$.

\section{Table 4: Influence of transdermal and oral ASA on PT and APTT as compared to control group}

\begin{tabular}{|c|c|c|c|c|c|}
\hline \multirow[t]{2}{*}{ Groups } & \multirow[t]{2}{*}{ Formulations } & \multicolumn{2}{|c|}{$\begin{array}{l}\text { PT (Seconds) } \\
(\text { Mean* } \pm \text { SD) }\end{array}$} & \multicolumn{2}{|c|}{$\begin{array}{l}\text { APTT (Seconds) (Mean* } \\
\pm \text { SD) }\end{array}$} \\
\hline & & Initial & 24 hrs & Initial & $24 \mathrm{hrs}$ \\
\hline Control & - & $9.3 \pm 0.1$ & $9.3 \pm 0.1$ & $28.3 \pm 1.91$ & $28.3 \pm 3.7$ \\
\hline Oral ASA & $\begin{array}{l}8 \mathrm{mg} \mathrm{ASA} \text { in } \\
1 \% \mathrm{w} / \mathrm{v} \mathrm{CMC} \\
\text { suspension in } \\
\text { water }\end{array}$ & $9.2 \pm 0.1$ & $8.9 \pm 0.1$ & $28.3 \pm 1.0$ & $32.17 \pm 4.7$ \\
\hline Patch II & $\begin{array}{l}\text { ASA ( } 8 \mathrm{mg}) \\
\text { formulated } \\
\text { using eudragit } \\
\text { copolymers }\end{array}$ & $9.3 \pm 1.1$ & $9.47 \pm 0.06$ & $28.2 \pm 0.91$ & $27.0 \pm 4.11$ \\
\hline Patch IIe & $\begin{array}{l}\text { ASA }(8 \mathrm{mg}) \text { in } \\
\text { eudragit } \\
\text { copolymers }+1 \\
\text { ml turpentine } \\
\text { oil }\end{array}$ & $9.2 \pm 0.99$ & $9.47 \pm 0.32$ & $28.3 \pm 1.91$ & $30.6 \pm 0.89$ \\
\hline Patch IId & $\begin{array}{l}\text { ASA }(8 \mathrm{mg}) \text { in } \\
\text { eudragit } \\
\text { copolymers }+1 \\
\text { ml lemon oil }\end{array}$ & $9.2 \pm 0.99$ & $10.2 \pm 0.10$ & $28.4 \pm 0.10$ & $32.78 \pm 3.25$ \\
\hline
\end{tabular}

*Results are the mean of eight observations, $n=8$.

\section{Discussion}

The increasing appreciation of the role of inflammation in atherosclerosis and thrombosis $[24,25]$ has raised intriguing possibility that aspirin the anti- inflammatory compound which was shown to reduce platelet aggregation induced by several physiological stimuli [1] - might be effective in the prevention of cardiovascular disorders, including myocardial infarction, stroke and thrombosis. The oral administration of ASA for the prevention of cardiovascular events has been associated with the elevated number of gastrointestinal side effects. This has limited its widespread clinical use.

Hence, the present study was designed to develop a transdermal therapeutic system for aspirin that could provide a predetermined constant drug delivery, and the use of chemical penetration enhancers to modulate skin permeation of aspirin which would be beneficial for an effective and safe therapy.

In 1971, Smith and Willis proved that the blood-thinning properties of aspirin are based on its inhibition of prostaglandin synthesis in the blood platelets. Because platelet aggregation was known to play a crucial role in thrombosis, it was anticipated that the newly described antiaggregating activity of aspirin might translate to a clinical benefit in ischaemic cardiovascular disease.

Based on the in-vitro permeation studies across rat skin, film II containing eudragit RL and eudragit RS in the ration of 5:1 provided 
maximum transdermal flux. It provided efficient matrix to build up a large reservoir of drug in the skin and to achieve greater permeation with a lower amount of drug. Greater penetration with a lower concentration of drug is always preferable as [26], has reported increased irritation on increasing drug concentration in the transdermal device.

ASA crystallizes easily from the solution, however, this tendency was substantially reduced when films were dried at lower temperature $(\leq$ $\left.15^{\circ} \mathrm{C}\right)$.

The permeation rate of aspirin was further enhanced by the incorporation of turpentine and lemon oil as penetration enhancers. Terpenes are receiving much attention as penetration enhancers [27]. They are derived from plant essential oils and combine good penetration enhancing abilities with low skin irritancy and low systemic toxicity. A number of terpenes viz. menthol, 1-8- cineol, dlimonene, nerolidol, geraniol, thymol, cyminine, carvone, acetylterpineol, $\alpha$-bisabool have been shown to increase transdermal permeation rate of hydrophilic and lipophilic drugs [28, 29].

Lemon oil in Patch IId significantly increased transdermal flux to $0.92 \mathrm{mg} / \mathrm{cm}^{2}$ over 24 hours. It is reported that $21 \mathrm{mg} /$ day of aspirin is required to be systematically available for inhibition of platelet formation [14]. Thus, ASA can be delivered transdermally by Patch IId of around 25 $\mathrm{cm}^{2}$ area in order to suppress the platelet aggregation. McAdam and co-workers [11] reported transdermal delivery of ASA $33 \pm 3 \mathrm{mg}$ daily from matrix type of patch in healthy volunteers that had a total surface area of $50 \mathrm{~cm}^{2}$ and contained $120 \mathrm{mg}$ ASA along with dlimonene at $12 \%$ of the total matrix mass. Our results showed a higher release from formulation containing lemon oil indicating that lemon oil facilitates the flux of ASA to a greater extent than that of turpentine oil.

In a clinical situation, both the bleeding time (BT) and a number of in vitro measurements such as prothrombin time (PT) and activated partial thromboplastin time (APTT) are used together to test the patient's homeostatic mechanism and to determine whether or not there is risk of bleeding. Aspirin has been proven effective in secondary prevention of coronary artery disease (CAD). Its efficacy has been ascribed to its antiplatelet action through the irreversible acetylation of platelet cyclooxygenase with subsequent blockade of platelet thromboxane synthesis. In this study, we evaluated the effects of dermal low-dose aspirin on blood coagulation in mice and rats using routine laboratory blood tests (BT, PT and APTT) as a measure of aspirin bioavailability.

Aspirin influences the bleeding time, presumably through the inhibition of prostaglandin biosynthesis and the resultant platelet secretion. The response of the bleeding time is quite variable after ingestion of aspirin. In some instances, the bleeding time is not prolonged, whereas in other instances there is definite prolongation [30]. The prolongation is dependent upon the technique used and direction of incision, but overall aspirin was found to produce only a modest increase in the bleeding time [31].

Comparison of the time courses for bleeding duration before and after the oral administration and transdermal application of ASA, showed that the formulated dermal low-dose aspirin (patch IId), containing lemon oil as penetration enhancer, significantly prolonged the bleeding time.

Taken together, our results provide convincing evidence for the feasibility of transdermal low-dose aspirin patch containing lemon oil as penetration enhancer in clinical situations because of excellent release of the drug, and its influence on the blood coagulation by means of affecting both the extrinsic coagulation system and the intrinsic coagulation system significantly. Further work is required to establish the utility of such transdermal drug delivery system through long term pharmacokinetic studies on human subjects.

\section{Acknowledgement}

We are thankful to the Indian Council for Cultural Relations for financial assistance towards research investigation.

\section{References}

1. De Gaetano, G. Aspirin and the prevention of ischemic heart disease. A Socratic dialogue

C 2010 by NWPII. All rights reserved. 
between a cardiologist, a clinical pharmacologist and an expert of blood platelets. Ital Heart J, 2001a, 2, 582-588.

2. American - Canadian Co-operative Study Group. Persantine aspirin trial in cerebral ischemia. part II; end point results. Stroke, 1985, 16(3), 406-415.

3. Eidelman, R.S.; Herbert, P.R.; Weisman, S.; Hennekens, C.H. An update on aspirin in the primary prevention of cardiovascular disease. Arch Int Med 2003, 163, 25-36.

4. Smith, J.B.; Willis, A.L. Aspirin selectively inhibits prostaglandin production in human platelets. Nature [New Biol.], 1971, 231, 235237.

5. De Gaetano, G. Historical overview of the role of platelets in hemostasis and thrombosis. Haematologica, 2001b, 86, 349-356.

6. The RISC Group. Risk of myocardial infarction and death during treatment with low-dose aspirin and intravenous heparin in men with unstable coronary artery disease. Lancet, 1990, 336, 827-830.

7. Derry, S.; Loke, Y.Y. Risk of gastrointestinal hemorrhage with long term use of aspirin: meta-analysis. Br Med J, 2000, 321, 1183-187.

8. Krishna, D.R.; Srinivas, A.G.; Srinivas, A. Transdermal aspirin: influence of platelet aggregation and serum lipid peroxides. Ind $J$ Pharm Sci, 2000, 62(3), 200-204.

9. Bronaugh, R.L.; Collier, S.W. In vitro methods for measuring skin permeation. In: Zatz, J.L. (Ed.), Skin Permeation - Fundamentals and Applications. Allured Publishing Corporation, Wheaton, Illinois, 1993, pp. 93-111.

10. Keimowitz, R.M.; Pulvermacher, G.; Mayo, G.; FitzGerald, D.J. Transdermal modification of platelet function: a dermal aspirin preparation selectively inhibits platelet cyclooxygenase and prevents prostacyclin biosynthesis. Circulation, 1993, 88, 556-561.

11. McAdam, B.; Keimowitz, R.M.; Maher, M.; FitzGerald, D.J. Transdermal modification of platelet function: an aspirin patch system results in marked suppression of platelet cyclooxygenase. J Pharmacol Exper Therap, 1996, 277, 559-564.

12. McMahon, G.P.; O’Connor, S.J.; FitzGerald, D.J.; Roy, S.L.; Kelly, M.T. Determination of aspirin and salicylic acid in transdermal perfusates. J Chromatography B, 1998, 707, 322-327.

13. Pederson, A.K.; FitzGerald, G.A. Dose-related kinetics of aspirin: presystemic acetylation of platelet cycolooxygenase. New Eng J Med, 1984, 311, 1206-1211.

14. Levang, A.K.; Zhao, K.; Singh, J. Effect of ethanol/ propylene glycol on the in vitro percutaneous absorption of aspirin, biophysical changes and macroscopic barrier properties of the skin. Int J Pharm, 1999, 181, 255-263.

15. Lee, J.S.; Adrie, C.; Jacob, H.J. Chronic inhalation of nitric oxide inhibits neointimal formation after balloon-induced arterial injury. Circulation Res, 1996, 78, 337-342.

16. The Dutch TIA Trial Study Group. A comparison of two doses aspirin (30 mg vs. $283 \mathrm{mg}$ a day) in patients after a transient ischemic attack or minor ischemic stroke. New Engl J Med, 1991, 325, 1261-1266.

17. Petersen, T.; Husted, S.E.; Pedersen, A.K.; Geday, E. Systemic availability of acetylsalicylic acid in normal human subjects after oral ingestion of three different formulations. Acta Pharmacol Toxicol, 1982, 51, 285-291.

18. Obata, Y.; Takayama, K.; Maitani, Y.; Nagai, T. Effect of pretreatment of skin with cyclic monoterpenes on permeation of diclofenac in hairless rat. Biol Pharm Bull, 1993, 16, 312314.

19. Okabe, H.; Takayama, K.; Nagai, T. Percutaneous absorption of ketoprofen from acrylic gel patches containing d-limonene and ethanol as absorption enhancers. Chem Pharm Bull, 1992, 40, 1906-1910.

20. Priborsky, J.; Takayama, K.; Obata, Y.; Priborska, Z.; Nagai, T. Influence of limonene and laurocapram on percutaneous absorption of nonsteroidal anti-inflammatory drugs. Arzneimittel - Forschung, 1992, 42, 116-119.

21. Hadgraft, J. Recent developments in topical and transdermal delivery. Eur J Drug Metab Pharmacokinet, 1996, 21(2), 165-173.

22. Lautes, I.J.; Chu, J.C.; Sikranth, S.; HuberLang, M. Anti-C5a Ameliorates coagulation/ 
fibrinolytic protein changes in a rat model of sepsis. Am J Path, 2002, 160, 1867-1875.

23. Brandt, J. T.; Triplett, D.A.; Rock, W.A.; Bovill, E.G.; Arkin, C. F. Effect of lupus anticoagulants on the activated partial thromboplastin time. Arch Pathol Lab Med, 1991, 115, 109-114.

24. Ross, R. 1999. Atherosclerosis: an inflammatory disease. New Engl J Med, 1999, 340, 115-126.

25. Libby, P. Inflammation in atherosclerosis. Nature, 2002, 420, 868-874.

26. Kobayashi, K.; Hosaka, T.; Ueno, H.; Maruo, M. Relationship between the amount of propranolol permeating through the stratum corneum of guinea pig skin and after application of propranolol adhesive patch and skin irritation. Biol Pharm Bull, 1996, 19(6), 839-844.

27. Williams, A.C.; Barry, B.W. Terpenes and the lipid protein-partitioning theory of skin penetration enhancement. Pharm Res, 1991, $8,17-24$

28. Cornwell, P.A.; Barry, B.W. Sequiterpene components of volatile oils as skin penetration enhancers for the hydrophilic permeant 5fluorouracil. J Pharm Pharmacol, 1991, 46, 261-269.

29. Gao, S.; Singh, J. Invitro percutaneous absorption enhancement of lipophilic drug tamoxifen by terpenes. J Cont Rel, 1998, 51, 193-199.

30. Mielke, C.H.; Kaneshiro, M.M.; Maher, I. A. The standardized normal Ivy bleeding time and its prolongation by aspirin. Blood, 1969, 34, 204-210.

31. Mielke , C.H. Aspirin prolongation of the template bleeding time: influence of venostasis and direction of incision. Blood, 1982, 60, 1139-1142. 